\title{
A Interpretação ambiental na conservação do patrimônio cultural: o caso do arqueosítio musealizado da (Real) Fábrica de Neve de Montejunto, Portugal.
}

Karina Gonçalves de Almeida Souza*

\section{Resumo}

O presente trabalho irá discorrer sobre a relação entre os elementos da Interpretação ambiental na conservação patrimonial, ao apresentar iniciativas do Programa de Salvaguarda e Valorização da (Real) Fábrica de Neve de Montejunto, Portugal. Nesta observação reflexiva será dedicada maior atenção à componente Interpretação do Programa em questão que objetivou valorizar as estruturas da antiga fábrica que se encontra in situ, e criar um circuito de visitação sinalizado, e orientado por investigação científica. Conceitos e princípios da Interpretação do Patrimônio fundamentarão a leitura do Programa de Salvaguarda e Valorização da (Real) Fábrica de Neve de Montejunto e da sua paisagem envolvente, na perspectiva de identificar elementos de auxílio nas iniciativas de conservação do patrimônio.

Palavras-chave: Interpretação ambiental. Patrimônio arqueológico. Programa de conservação.

Environmental interpretation of cultural heritage conservation: the case of archaeological settlement musealize the (Real) Factory Snow Montejunto

\section{Abstract}

This paper will discuss the relationship between the elements of environmental interpretation in conservation heritage, by to present initiatives of the Program of Protection and Exploitation of (Real) Factory Snow Montejunto, Portugal. In reflective observation will be devoted more attention to the interpretation component of the program in question, which aimed to enhance the structures of the old factory which is in situ, and create a circuit of visits signaled, and guided by scientific research. Concepts and principles of Heritage Interpretation explain the reading program for the Protection and Exploitation of (Real) Factory Snow Montejunto and its 
surroundings with a view to identify elements of aid initiatives in heritage conservation.

Key-words: Environmental interpretation. Archaeological heritage. Conservation program.

\section{Introdução}

O presente artigo aborda questões sobre a aplicação da Interpretação como ferramenta auxiliar na conservação do patrimônio cultural, ao apresentar o Programa de Salvaguarda e Valorização da (Real) Fábrica de Neve de Montejunto, na Serra do Montejunto, Portugal. A função social atribuída à Fábrica da Neve de Montejunto como patrimônio arqueológico, Monumento Nacional (1), e área natural protegida para uso público contemplativo do conjunto de valores paisagísticos, construídos, técnicos, econômicos e sociais existentes, supõe a necessidade de sua defesa e recuperação do grau de apreciação dos residentes locais e demais visitantes.

O sítio da Fábrica da Neve de Montejunto figura dentre as tipologias da Nova Museologia (2), um arqueosítio musealizado, polinucleado na sua envolvente ecológica (3) e territorial, que integrado aos núcleos expositivos Centro de Interpretação Ambiental e Percursos Pedestres, constitui o espaço de visitação da Paisagem Protegida da Serra do Montejunto.

O objetivo de apresentação do Programa de Salvaguarda e Valorização da (Real) Fábrica de Neve de Montejunto no contexto dessa discussão é refletir sobre uma experiência prática de aplicação de técnicas de Interpretação para o resgate da memória histórica do território, para a sua valorização e promoção na dinâmica de animação cultural local.

Para tanto o texto se inicia com uma breve leitura histórica e conceitual da Interpretação como fundamento teórico. No segundo capítulo é apresentada a localização da Serra do Montejunto, em aspectos da geografia, arqueologia, geologia; o estatuto de Paisagem Protegida da área do sítio da Fábrica da Neve e entorno. No terceiro capítulo a Fábrica da Neve é tratada como objeto do Programa 
de Salvaguarda e Valorização da (Real) Fábrica de Neve de Montejunto, com ênfase para alguns aspectos relevantes da história, estrutura e funcionamento do complexo fabril. O quarto capítulo apresenta o Programa de Salvaguarda e Valorização da (Real) Fábrica de Neve de Montejunto, e destaca o componente da Interpretação, a partir do cruzamento entre a teoria e a leitura do espaço selecionado como estudo de caso. A investigação científica é aqui valorizada como uma etapa necessária que pressupõe qualquer iniciativa de conservação. O quinto capítulo é dedicado ao Centro de Interpretação Ambiental da Serra do Montejunto, na perspectiva de sua atuação como técnica de Interpretação específica e espaço contentor, seguido das considerações finais.

Este artigo é parte do resultado de minha pesquisa para trabalho final do mestrado em Museologia na Universidade Nova de Lisboa, onde investigo o Centro de Interpretação da Paisagem Protegida da Serra do Montejunto e o arqueosítio da Fábrica da Neve de Montejunto, como equipamentos museológicos contemporâneos, portanto carregados de significados e relevância para a conservação do patrimônio cultural e ambiental.

\section{A Interpretação para a conservação do patrimônio}

O termo "interpretação", ligado a uma prática de comunicar o patrimônio, começa a ser utilizado somente no final do século 19, apesar de ser uma das práticas mais antigas de transferência cultural (UZZEL, 1989 apud MORALES, 2001, p. 16). A utilização do termo e o desenvolvimento das práticas esteve ligado à instituição dos parques nacionais norte-americanos, inspirados na ideia de uso público e da conservação da natureza, ainda que o fazer interpretativo tenha uma origem anterior. A questão do desenvolvimento e da preservação dos parques era influenciada pelas características da vida social e cultural norte-americana, que à época criou uma crescente demanda pelo ócio e lazer nestes espaços naturais, e consequentemente um esforço maior da sua administração para atender tal demanda.

Freeman Tilden (2006, p.19), primeiro autor a publicar (4) sobre o tema, definiu a Interpretação (5) como uma atividade de caráter essencialmente educativa, porém menos erudita e cientificista. Entretanto, o emprego do termo "educativo" se prestou 
a muitas confusões, posto que nos países anglo-saxões, "educativo" leva a pensar em escolas e em um marco curricular. Na maioria dos espaços em que a Interpretação é empregada, está exposta como uma espécie de educação optativa, superior em certos aspectos à recebida em uma aula, já que se "enfrenta" o objeto de estudo em questão. A intenção, portanto, era usar a Interpretação como um meio de educação não-formal (6), pela apresentação de aspectos que ajudem a audiência a entender e apreciar os conteúdos, descobrir significados intrínsecos, provocar e estimular a curiosidade do visitante, assim como envolvê-los num processo de comprometimento na preservação ambiental.

Em meados dos anos de 1970, a Interpretação evolui de uma prática incipiente, e passa a ser usada não apenas em áreas rurais, mas em ambiente urbano, nos monumentos, edifícios e sítios históricos, vilas e cidades, e estendida a espaços como zoológicos, museus, jardins botânicos, sítios históricos e arqueológicos. Foi o tempo das caminhadas pelos centros urbanos e suas áreas verdes que, com a ampla participação de professores, estudantes, comerciantes e moradores, recuperaram e valorizaram áreas históricas, comerciais e de lazer para uso da população e do crescente número de visitantes (7).

Segundo Murta \& Albano (2002, p. 15), na década de 1980, o Planejamento Interpretativo ganhou maior destaque, passando a ser questão habitual em conferências e publicações na pauta de revitalização e promoção do patrimônio ambiental urbano e suas áreas rurais adjacentes. Novas formas de apresentação do patrimônio começam a se delinear - os open air museums, neighborhood museums, ecomuseus e "Centros de Interpretação Ambiental", são alguns exemplos. Estes últimos tornaram-se cada vez mais populares à época, e de modo problemático em alguns aspectos, na medida em que foram privilegiados apenas os espaços, e confundiu-se os esforços de interpretação com a simples associação à infraestrutura e equipamentos.

Nesse contexto, o Planejamento Interpretativo passa a ser utilizado cada vez mais por gestores de espaços de importância patrimonial abertos ao público em todo mundo, para suprir a carência de um tipo de apresentação na qual o visitante possa ter, além da informação, uma experiência enriquecedora e um contato mais próximo 
com a realidade do local visitado. Através da sensibilização para a preservação, a Interpretação cresce como processo de comunicação estimulando novas descobertas e despertando atitudes de proteção em turistas, comunidades locais, e empreendedores. Ao compreender o sentido do que vêem, ao apreciar sua experiência com o lugar e com as pessoas, os visitantes sentem-se enriquecidos com a convivência e com o que aprendem informalmente enquanto se divertem em seu tempo de lazer. Acabam por valorizar mais a cultura local e o patrimônio.

No Brasil, a divulgação da prática da Interpretação teve na ECO 92, no Rio de Janeiro, um amplo panorama de discussões acerca da "sustentabilidade", termo do qual foi criada a sua definição e a constatação da necessidade de se desenvolver a atividade turística de maneira sustentável, sendo a cultura uma estratégia potencial. Em 1999 acontece a Conferência Internacional "Apresentação e Interpretação na Europa", para avaliar a prática e o futuro da Interpretação patrimonial, e onde se levantou a questão de que não bastava tombar, restaurar o patrimônio ou delimitar áreas de proteção se não fosse desenvolvido afeto entre os visitantes e o lugar. Em 2000, foi instituída oficialmente a Rede Europeia para Interpretação do Patrimônio (Interpret Europe), criada para divulgar experiências bem sucedidas de teoria e práticas atuais da Interpretação.

Como os trabalhos fundamentais da Interpretação privilegiaram as áreas rurais, parques e reservas nacionais, e as suas práticas estiveram sempre ligadas à disseminação de atividades de educação ambiental, isso lhe deu um maior mérito e popularidade como Interpretação Ambiental, tendo os Centros de Visitantes por vezes, sobretudo na Europa, a denominação de Centros de Interpretação Ambiental.

\section{A Serra do Montejunto - localização da envolvente ecológica}

A Serra do Montejunto está situada na região centro de Portugal, entre os $39^{\circ} 14^{\prime}$ $39^{\circ} 14^{\prime}$ 'Norte e os meridianos $8^{\circ} 59^{\prime}-9^{\circ} 07^{\prime}$ ' Oeste, numa barreira montanhosa paralela à linha da costa $20 \mathrm{~km}$, que faz transição entre o Oeste e o Vale do Tejo. O topo da Serra do Montejunto é o mirante natural mais alto da Estremadura (8), com uma área de cerca de 5.400 ha, constituída por um conjunto de elevações de rocha calcárea com 15 metros de comprimento, $7 \mathrm{kms}$ de largura, chegando o ponto geodésico principal a atingir os 666 metros acima do nível do mar. 
Nesta serra os calcáreos do Jurássico são dominantes, existindo forte ligação entre a origem da Serra do Montejunto com o movimento das placas tectônicas. Em período anterior, há 200 mil anos, em que todos os continentes faziam parte de uma única "massa", ocorreu a fraturação, paralela ao atual litoral português, que separou Portugal das Américas e África.

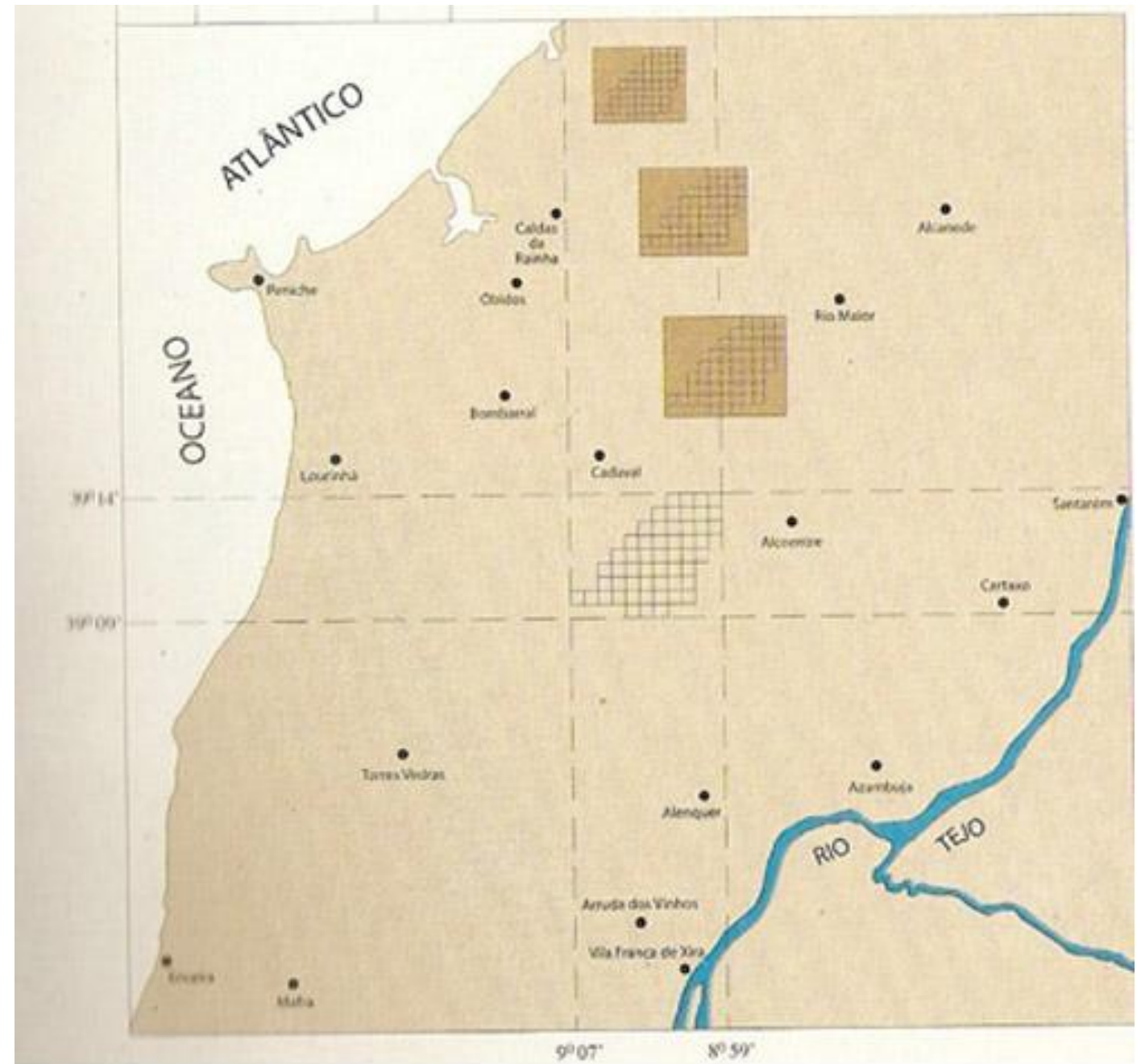

Figura 01. Localização da Serra do Montejunto. In: Atlas das Aves que Nidificam na Serra do Montejunto (BARROS; MARQUES, 1999).

Como uma "ilha" em relação à região envolvente, bastante humanizada com a prática de uma atividade agrícola e silvícola intensa, Montejunto é um dos poucos locais de refúgio para muitos animais em toda esta região. Constitui hoje um dos últimos refúgios para algumas espécies de animais em toda a região Oeste e Vale do Tejo, estando abrigadas cerca de 500 espécies de flora diferentes, raras e de 
endemismos pouco frequentes (9); cerca de 75 espécies nidificantes (10) e com uma flora onde o carrasco e o alecrim já foram dominantes, atualmente reflorestada (11) por carvalhos, pinheiros, cedros e castanheiros (BARROS; MARQUES, 99, p. 16).

A beleza natural e as condições de habitat que a Serra do Montejunto oferece foram desde alguns milhares de anos motivo de atração para o homem. Tal fato tornam frequentes os estudos arqueólogos sobre os tipos de ocupação dos povos que procuraram a zona e nela se fixaram. A arqueologia está, portanto, presente na região nos vários vestígios ali existentes, que demonstram esta ocupação. Viviam em grutas, depois em montes onde edificaram os castros (12), e aos poucos esses cenários evoluíram às aldeias e vilas que hoje se conhece, com campos agrícolas nos solos cultiváveis e mais acessíveis, resultando nos impactos previstos na paisagem por conta dos pastos dos rebanhos, do corte de lenha e da retirada das pedras para a construção das casas.

Pelo reconhecimento da zona como importante repositório natural de vegetação, afloramentos rochosos, fauna, etc, bem como o potencial paisagístico com grande beleza cênica, nesta área da Fábrica da Neve de Montejunto e adjacência, foi criada a Paisagem Protegida pelo Decreto Regulamentar n¹1/99 (13). A legislação prevê que este sítio seja apropriado à promoção de melhoria na qualidade de vida das comunidades de seu entorno, e que sejam apropriadas a estes e demais visitantes o desenvolvimento de atividades educativas/recreativas e de lazer contemplativo.

Após a classificação da Paisagem Protegida da Serra do Montejunto, foi criado o Centro de Interpretação Ambiental para permitir condições de usufruto coletivo, com uma proposta que ajudasse tecnicamente a explicar a fauna e flora, e pudesse mostrar as rotas de visitação pré-estabelecidas que levarão o visitante a interiorizar o espírito da natureza, sem que isso implique ameaça de agressão ao meio.

O Centro de Interpretação Ambiental da Serra do Montejunto com o núcleo expositivo da Paisagem Protegida, dá suporte para visitação a toda região, e tem como seu espólio mais significativo a composição das espécies animais e vegetais abrigadas na área que compreende a Área Natural Protegida, bem como os achados arqueológicos da antiga Fábrica da Neve. Esta "coleção" tem a singularidade de 
possibilitar a contemplação pelos visitantes com espécies animais ameaçadas de extinção, raras, e endêmicas. Aliado a isso, a possibilidade de contato com as ruínas desse monumento único em seu tempo, no estado satisfatório de conservação em que se encontra; permite que uma visita a esse conjunto patrimonial possa ser comparada num panorama museológico tradicional à valoração dada em se estar, por exemplo, diante de uma obra de arte famosa e rara.

\section{Fábrica da Neve de Montejunto - objeto de investigação para a conservação}

Os achados arqueológicos da antiga Fábrica do Gelo de Montejunto são de incontestável relação com a memória do passado e imaginário das comunidades locais, e componentes da área ambiental e arquitetônica. Constituiu-se num conjunto fabril correspondente aos tempos áureos em que Portugal desenvolveu a exploração, o aperfeiçoamento do próprio sistema de fabrico do gelo - que tinha modelo na conservação e arquétipos importados da França e Espanha - e nas expedições do gelo para Lisboa em finais do século 18/19 (FOLGADO, 2010, p. 42). Integrava-se numa unidade agrícola, construída para suprir faltas no abastecimento do Gelo em Lisboa, pelas geleiras da Serra da Estrela e Lousã.

A prática do consumo do gelo em Portugal é atribuída ao rei Felipe II, em meados do século 17. À época o gelo era usado para produção de sorvete, para refrigerar bebidas, conservar medicamentos e outros fins terapêuticos. "[...] Por ser um método de obter da natureza mais ou menos artificioso, o gelo não foi sempre tão fácil, nem tão barato, nem para todos" (FOLGADO, 2010, p. 37). O aumento do consumo e da importância do produto, na corte e na cidade, impulsiona maiores esforços de produção e comercialização.

Fabricava-se gelo na (Real) Fábrica do Montejunto, diferente de outros pontos da Europa onde se procedia essencialmente a recolha natural da neve. A tecnologia de fabrico vinha da Itália, mas Portugal, por ter um clima mais temperado que os países do mediterrâneo, apresentava a particularidade de adaptação, por exemplo, nos tanques onde se obtinha o gelo que era compartimentado, com divisórias em menor dimensão que ajudavam no congelamento mais rápido. $O$ resultado do método demonstrava uma certa expertise de Portugal. 
Segundo Folgado (2010, p. 39) a designação de "Real" à Fábrica de Neve de Montejunto é errônea. Em sua pesquisa foram inexistentes informações sobre fábricas de gelo ou neve nos fundos do Ministério do Reino e da Junta de Comércio, organismos responsáveis pela regulamentação da atividade econômica entre 1757 e 1834. Mesmo com o seu produto final sendo o obtido através do congelamento da água em tanques e depois expostos às condições climáticas, tanto os poços como a própria designação do ofício "Neveiro", acabam por aparecer associados à palavra neve, o que faz pensar ser a neve o produto da recolha (FOLGADO, 2010, p. 38). A designação de "Real", além de fazer parte do imaginário, acaba por figurar uma temática a ser utilizada em termos interpretativos.

O seu princípio funcional parece inalterado, compartilhando do universo cultural e técnico da edificação dos tanques da época na Europa. Do complexo fabril subsistiram evidências materiais que permitem estabelecer o circuito de fabricação desse produto. É constituído em dois grupos de construções, distribuídos em: I) Área de Fabrico, II) Área de Armazenamento, com espaços funcionais caracterizados como indicado nas legendas da figura a seguir:

I) Área de fabrico - constituída por dois poços de captação de água (d), uma casa onde eram acionadas as noras (c) - e que servia também de armazém - e um tanque grande de pré-enchimento (b). Este espaço abriga ainda a zona de fabricação do gelo por processo natural (a) - composta por um conjunto de quarenta e quatro tanques de pequena profundidade, articulados entre si por um sistema de condução de água a partir do tanque grande da área de extração. Os dois poços, ainda hoje, fornecem água ao aquartelamento da Força Aérea e às poucas habitações locais (LOURENÇO; CARVALHO, 1991, p. 147-152).

II) Área de armazenamento e expedição do gelo (e) - distante cerca de 100 metros da zona do fabrico, consiste num edifício composto por uma sala retangular, onde se procedia a manufatura do gelo (14), três silos que serviam de armazém e depósito de conservação até posterior distribuição. Os silos possuem diferentes dimensões. O silo ao centro possui formato circular com cerca de 10 metros de profundidade por 7 metros de diâmetro, e duas portas de acesso. Um gancho de ferro fixado no interior ao lintel servia para facilitar a descida ou elevação dos blocos de gelo até ao 
nível da porta. Os outros dois silos, que ladeiam o principal são retangulares e têm profundidade de cerca de 4 metros. Não possuem ligação entre suas estruturas, o que faz supor terem sido construídos quando da remodelação da Fábrica em 1782 (LOURENÇO; CARVALHO, 1991, p. 98). "As grossas paredes dos silos, a sua profundidade e a sombra dada pelo arvoredo circundante, criam uma temperatura ambiente no interior, suficiente para manter o gelo solidificado" (LOURENÇO; CARVALHO, 1991).

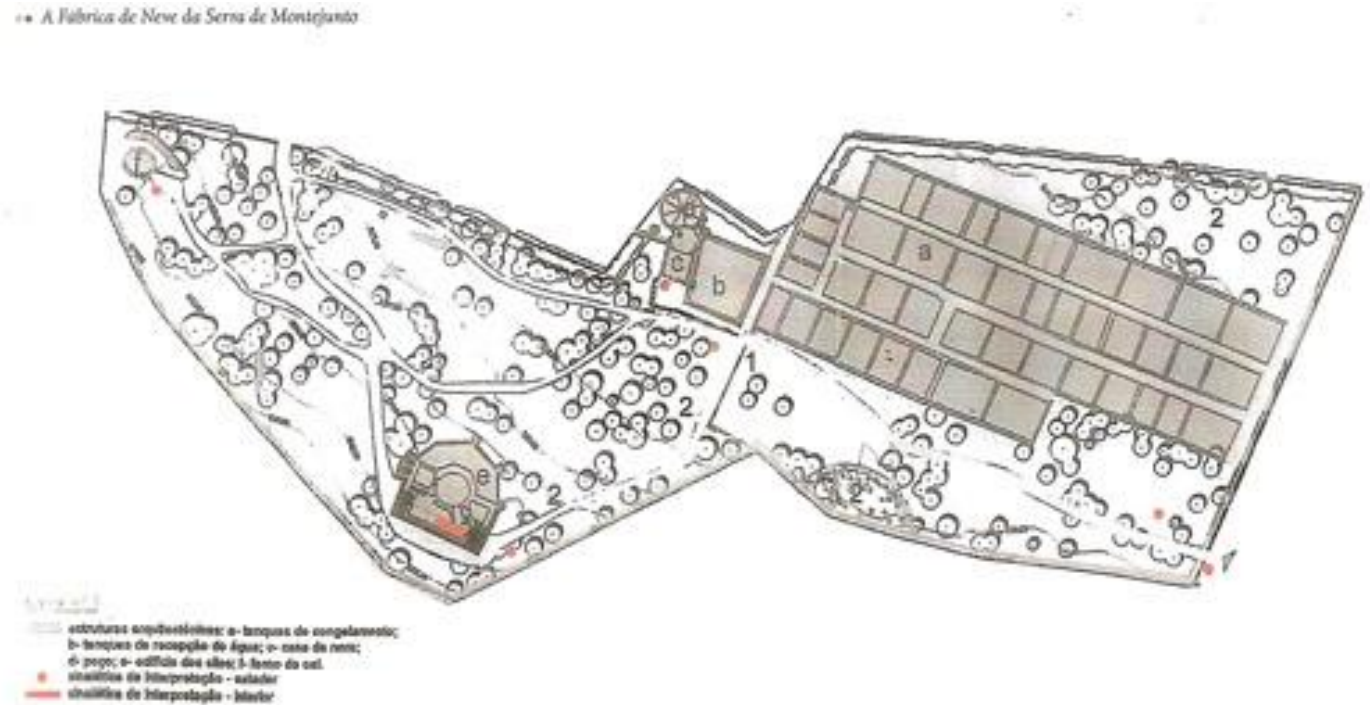

Planta reativas ao projecto de sinalteica de interpretaglo, 2005. tuaber Pemena wak

Figura 02 - Plana arquitetônica da Fábrica da Neve de Montejunto, com legendas em vermelho relativa ao projeto de sinalética de interpretação. Fonte: Elisabete Ferreira. IPPAR, 2005 In FOLGADO. Deolinda, LACERDA, Manuel. O programa de salvaguarda e valorizaçăo. Do conceito à prática. A Fábrica de Neve da Serra do Montejunto. Cadaval: Cåmara Municipal do Cadaval, 2010.

De decoração típica do século 18 , o local é também considerado pelo imaginário popular como capela, um espaço de sacralização e devoção na defesa dos interesses dos neveiros, já que ali poderia "morrer" todo o trabalho do neveiro. Especula-se ainda que "na parte superior do seu pórtico, num pequeno nicho agora vazio, existiu segundo testemunhos, uma imagem de N. S. das Neves, a qual desconhecem o seu paradeiro" (LOURENÇO; CARVALHO, 1991, p. 147-152). Uma lápide que ornamentava a sua entrada fora encontrada quando dos trabalhos de escavação e limpeza do silo principal, e refere o ato da compra e reedificação da Fábrica por Julião Pereira de Castro, capitão da Malta, "reposteiro" e "neveiro" da Casa Real, que data 1782. Infere-se que a fábrica já funcionava em datas anteriores, 
embora talvez com uma produção inferior (LOURENÇO; CARVALHO, 1991, p. 147152).

Existe ainda um forno de produção de cal, cuja data de construção é atribuída à mesma época. Era utilizado para transformar a rocha calcárea, por combustão direta à lenha em matéria-prima a formação da argamassa usada na construção da Fábrica da Neve e de outras estruturas como as casas de habitação. Coloca-se também a hipótese da cal ser também utilizada na desinfecção da água, "a exemplo do que acontecia nas cisternas urbanas, monásticas o privadas" (CUSTÓDIO, 2010, p. 22).

O que se conhece do processo de fabrico do gelo é do relato oral da comunidade de Pragança e aldeamentos vizinhos. A produção acontecia durante o inverno, quando os que ali trabalhavam enchiam o tanque de pré-enchimento ao cair da tarde, e este desaguava aos tanques rasos de congelamento, onde sob as baixas temperaturas condençava-se. Antes de amanhecer esse gelo era retirado e transportado em cestos até o edifício dos silos de armazenamento.

O transporte até os centros de consumo era a fase que exigia maior cuidado no processo, para que houvesse o mínimo possível de perdas. Como tal são concedidos "privilégios e insenções" pelo rei aos neveiros (15). O transporte era composto por carruagens de tração animal para descer a Serra do Montejunto, para depois seguir em carros ou direto aos barcos na vala do Carregado, até chegar ao Terreiro do Paço. Já em Lisboa, era feita a distribuição do gelo nas lojas existentes na Praça do Comércio, Rossio e na Casa Real, atual café Martinho da Arcada, que ganhou fama a esta época pelos sorvetes e bebidas geladas que vendia.

Nesse contexto encontram-se os neveiros (16), a quem se atribuía o ofício de comercialização da neve/gelo, estes com claros privilégios; e a quem concedia-se o direito de exploração dos poços ou áreas de armazenamento da neve/gelo, que também podia comercializar o produto, mas para o qual não se encontrou nenhum privilégio de classe (FOLGADO, 2006, p. 40). Julião Pereira de Castro, proprietário da Fábrica da Neve de Montejunto e dos poços de neve na Serra da Lousã, reedificou aquela em 1782, quando já em funcionamento abastecia a casa real há 
cerca de vinte e cinco anos. Da remodelação incluem-se os dois tanques reservatórios, uma casa de nora e um poço de expedição do gelo (FOLGADO, 2006, p. 42).

A Fábrica da Neve de Montejunto teria tido fases de crescimento até ser fechada com o fim da exploração do gelo nos finais de 1800. A partir de então, o espaço funcional da Fábrica da Neve é modificado, remetendo este espaço vocacionado à agricultura para o cultivo de cereais. A área é expropriada pelo Estado (17) por considerar a então propriedade da Quinta da Serra como de utilidade pública, que inclui a zona como de utilidade pública no regime florestal parcial os terrenos baldios da Câmara Municipal de Alenquer e Cadaval, constituindo o perímetro de arborização denominado Montejunto (18).

\section{O Programa de Salvaguarda e Valorização da (Real) Fábrica da Neve de Montejunto}

Com o surgimento da museologia industrial em Portugal, pós 25 de abril de 1974, as ruínas da Fábrica da Neve de Montejunto ganham interesse da comunidade científica motivando iniciativas de identificação, (re) descoberta e intervenção para a sua preservação enquanto patrimônio industrial, que se afirmam na Exposição de Arqueologia Industrial na Central do Tejo (1985), na fundação da APAl - Associação Portuguesa de Arqueologia Industrial (1986) e na Conferência Intercalar Internacional do TICCIH - The International Commitee for the Conservation of the Industrial Heritage. Neste encontro a opinião dos representantes dos 14 países da Europa, Estados Unidos e do Canadá e membros do TICCIH foi unânime em considerar a Fábrica da Neve como um caso único de originalidade das suas estruturas e pelo razoável estado de conservação, foi representativa para esta decisão (CUSTÓDIO, 2010, p. 83-84).

Após a classificação da Fábrica da Neve de Montejunto como Monumento Nacional procedeu-se a recuperação total do edifício principal do conjunto fabril onde se situam os silos de armazenamento do gelo, e estruturas dos tanques de congelamento, trabalhos de preservação e restauro dos achados arqueológicos impulsionados desde o início da década de 1980. A primeira campanha de limpeza das estruturas da fábrica, foi um trabalho integrado ao II Campo Internacional de 
Trabalho da Serra do Montejunto e programa ocupacional OTL, teve apoio do Instituto Português da Juventude, Câmara Municipal do Cadaval, IPPAR Esquadrão 11 da Força Aérea Portuguesa e Instituto Florestal, em 1998 (CARVALHO, 1996, p. 137-151).

Objeto de musealização, de elementos singulares que possam converter à interpretação do espaço, em 2005 fora idealizado um programa para valorização da Real Fábrica da Neve de Montejunto, trabalho iniciado pelo então IPPAR, atual IGESPAR - Instituto de Gestão do Patrimônio Arquitetônico e Arqueológico, e desenvolvido em conjunto com a Câmara Municipal do Cadaval que solicitou apoio na elaboração de um Projeto Interpretativo para musealização do sítio arqueológico, e Interpretação do espaço Fábrica da Neve de Montejunto. O Projeto envolve a definição dos conteúdos, das representações gráficas, da distribuição espacial, iluminação, segurança, para comunicar o sítio arqueológico, com os seguintes componentes:

1- Arranjo paisagístico;

2- Conservação e restauro das estruturas de congelamento e armazenamento;

3- Interpretação e qualificação do circuito da visita, sinalética e conteúdos.

Para a área exterior das ruínas da Fábrica da Neve, o conceito apresentado é o de intervenção mínima no espaço, de modo a preservar ao máximo a identidade do lugar da fábrica. A interpretação deste conjunto pretendeu valorizar as estruturas da Fábrica que se encontram "in situ, através da criação de um conjunto de mensagens que procuram descodificar tanto os aspectos funcionais como os elementos menos tangíveis, recorrendo a um discurso claro e acessível" (FOLGADO, 2009, p. 123). No projeto executado pelo IGESPAR e Câmara do Cadaval consta uma sinalização em cada um dos núcleos da antiga fábrica num total de cinco painéis exteriores, e uma estrutura multiexpositiva (19) no interior do edifício dos silos de armazenamento que explique mais do processo do fabrico - a manufatura do Gelo, estabelecendo um circuito de visita.

A proposta para Interpretação da Fábrica da Neve de Montejunto prevê que seja garantida a manutenção dos vestígios do passado, entretando dinamizando a sua 
integração e comunicação com o presente, trabalho denominado Interpretação (FOLGADO, 2010, p. 122-123).

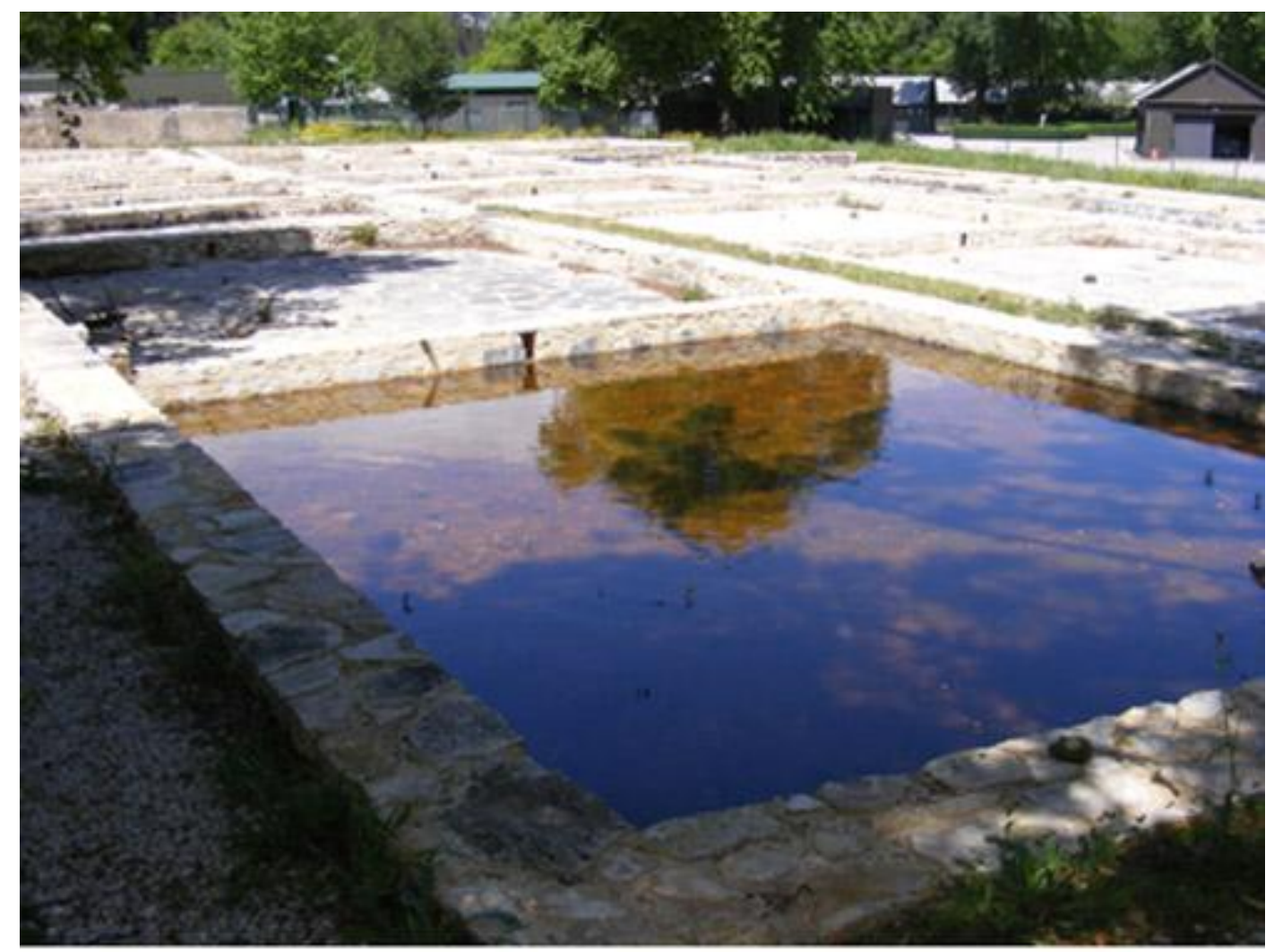

Figura 03 - Vista dos tanques rasos de congelamento. Fotografia: Karina Souza 


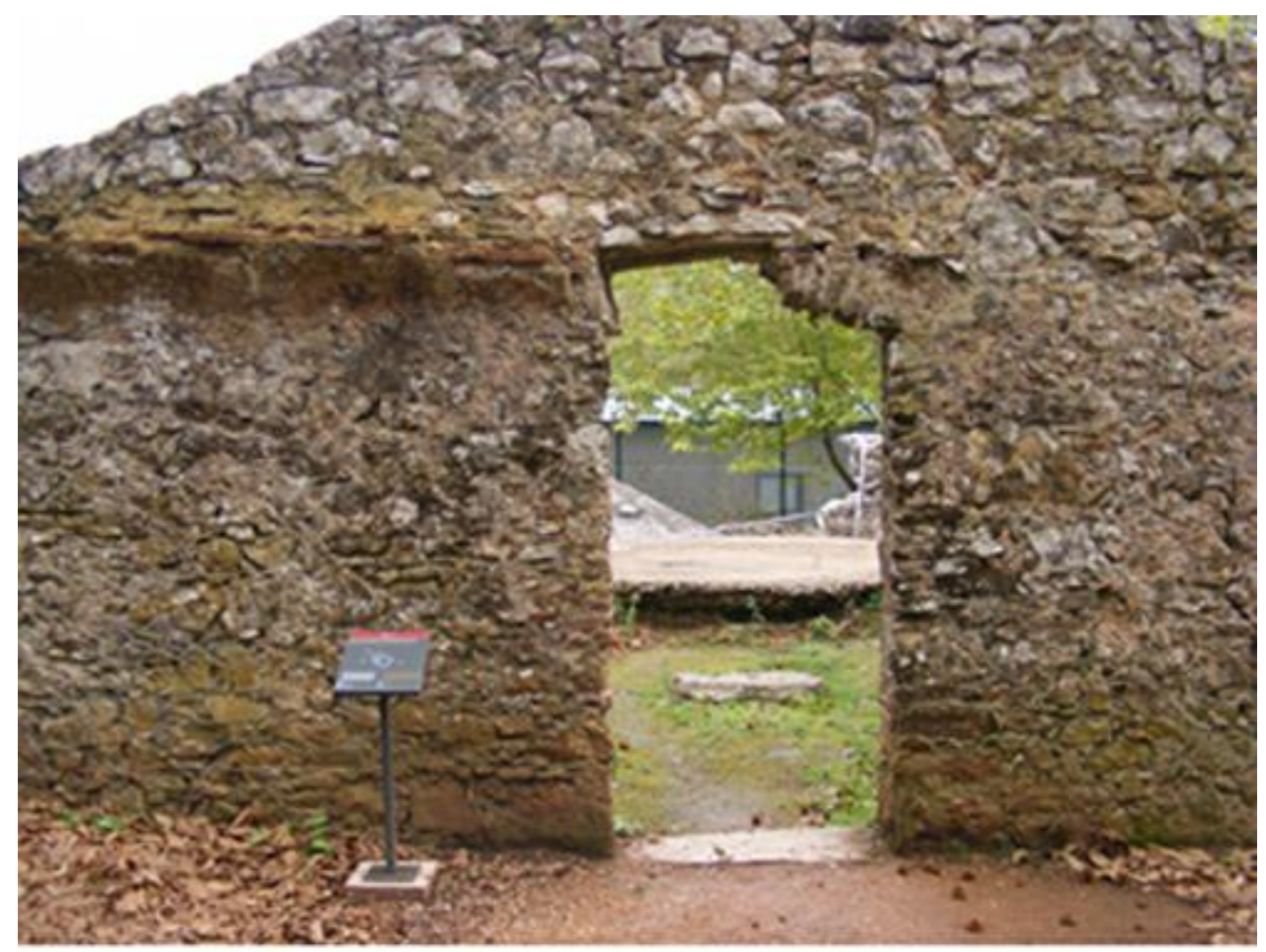

Figura 04 - Vista das ruínas da casa da nora e tanques de captaçăo de água. Fotografia: Karina Souza

As temáticas abordadas pelos textos expostos refletem-se em títulos como "A neve e o gelo natural como produtos"; "A Fábrica da Neve da Serra do Montejunto", "O Comércio do Gelo natural"; e "Os proprietários da Quinta da Serra" (FOLGADO, 2010, p. 124). Ainda no mesmo sistema de painéis contextualiza-se a visita ao sítio incorporando esta estrutura produtiva no seu ambiente natural, perspectiva que pode ser ampliada no Centro de Interpretação Ambiental - Área de Paisagem Protegida da Serra do Montejunto), que se encontra implantado nas proximidades da Fábrica da Neve (FOLGADO, 2010, p. 124). 


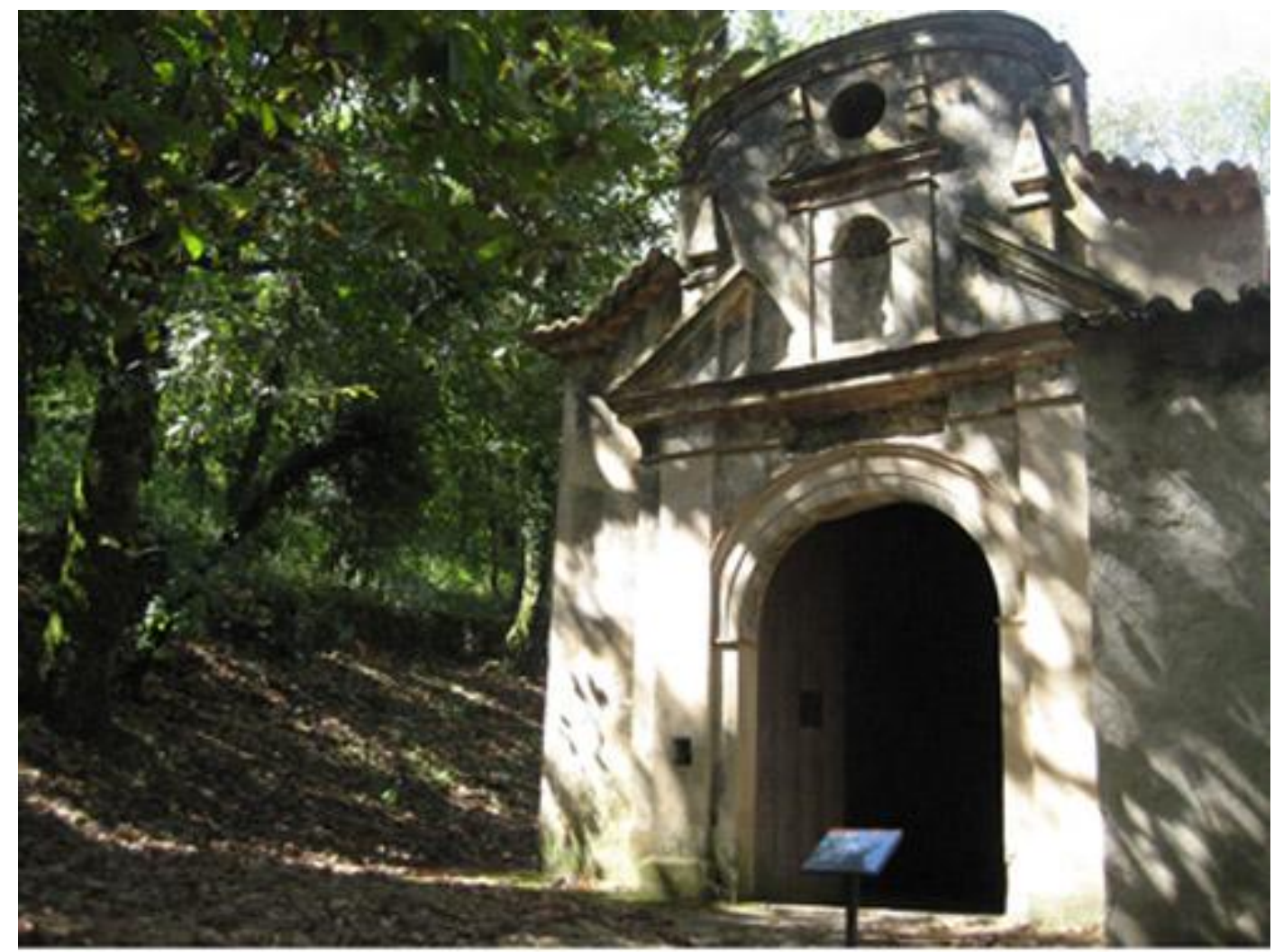

Figura 05 - Edifício dos silos de armazenamento com sinalização exterior. Fotografia: Karina Souza

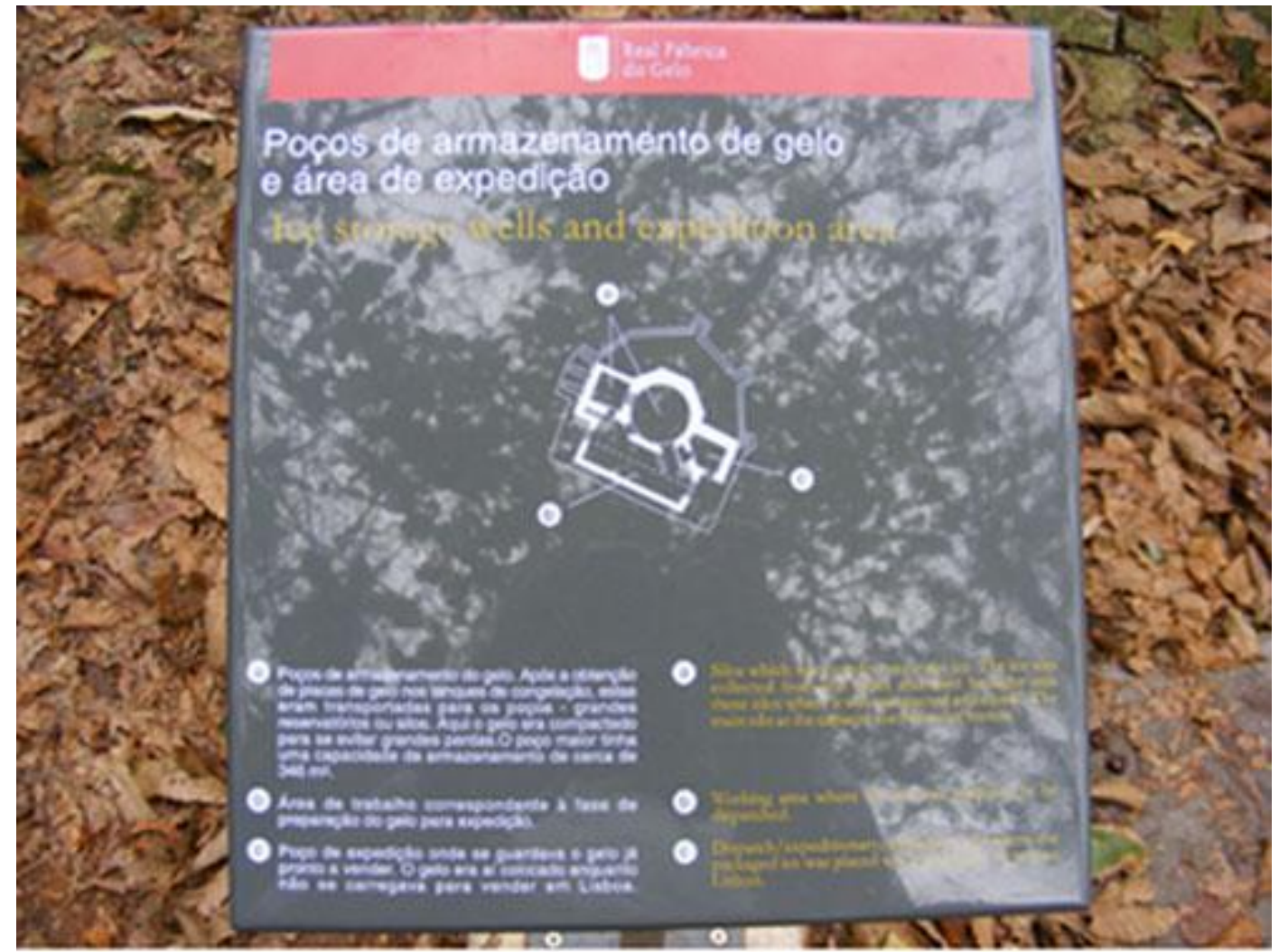

Figura 06 - Aspecto da sinalização exterior ao edifício dos silos de armazenamento. Fotografia: Karina Souza 


\section{Centro de Interpretação Ambiental da Paisagem Protegida da Serra do Montejunto - objeto e espaço contentor}

Para além das intervenções na Fábrica da Neve, a Interpretação está presente na Paisagem Protegida da Serra do Montejunto no Centro de Interpretação Ambiental, nos percursos pedestres e atividades outdoor com grupos escolares. Os Centros de Interpretação Ambiental (20) são espaços de apoio a uma variedade de programas e atividades de animação cultural desenvolvidos, por exemplo, por uma unidade de conservação ou outro espaço de importância patrimonial aberto à visitação, estabelecimentos cujas características os aproximam dos museus, posto que não Ihes seja atribuído habitualmente esse estatuto.

Como núcleo expositivo de um espaço de importância patrimonial, de apoio a programas educativos, atividades de campo e de investigação, um Centro de Interpretação Ambiental consiste em si na própria técnica de interpretação, e das mais eficientes por permitir abrigar ainda tantas outras.

Geralmente são formatados em contexto de ambientes naturais, pela gestão da área, para favorecer um conjunto de funções a serem realizadas em atenção aos visitantes reais e potenciais. Sendo esta opção de avançar com as infraestruturas de acolhimento, provocação e acesso à visitação em áreas protegidas como um todo, antes de ter que exercer o papel repressor, por vezes há uma estratégia de gestão da imagem institucional.

A casa que hoje abriga a exposição, foi outrora casa da guarda-florestal, desabitada em 1999 quando da instituição da Paisagem Protegida. A envolvente ecológica presente no território reforça a identidade do espaço museal polinucleado, e reflete harmonia nas linhas arquitetônicas não suntuosas. A renovação de funções do patrimônio quando da inserção da sua memória na fruição presente da animação sócio-cultural deve permitir a manutenção dos vestígios do passado na comunicação presente (FOLGADO, 2010, p. 122). De fato a conversão da antiga casa de guarda para núcleo expositivo carrega de autenticidade a sua função de espaço contentor às atividades ali desenvolvidas, e possibilita usar tal fato como tema para interpretação. 
Intervenções interpretativas na arquitetura de imóveis classificados, como a Fábrica da Neve de Montejunto, como uma medida de salvaguarda promovem todo um processo de melhoramento das condições do imóvel, sendo uma prática cada vez mais presente de incentivo por parte dos órgãos de Administração Central (FERREIRA, 2010, p. 116).

A exposição do Centro de Interpretação Ambiental da Serra do Montejunto segue uma linha programática de apresentar a fauna e flora dos ecossistemas característicos do maciço calcário; os aspectos geológicos e climáticos a relação de ocupação do homem com a serra desde o homem pré-histórico; a agricultura, silvicultura, arquitetura; manisfestações culturais e religiosas; e a Fábrica da Neve. Inclui ainda as informações de acesso às redes de visitação pré-estabelecidas, que são os percursos pedestres. Há ainda um painel dedicado à divulgação do Museu Municipal do Cadaval.

O caráter da exposição é permanente, e desde a inauguração não houve renovação. O espaço dispõe de um equipamento áudio-visual, um multimídia, uma maquete que representa a silhueta montanhosa da Serra do Montejunto, e sinaliza as localidades do entorno. A área expositiva é composta ainda de um pequeno auditório com capacidade para 35 pessoas sentadas, onde é exibido um vídeo sobre aspectos da ecologia da Paisagem Protegida.

O recurso base da comunicação expositiva consiste em painéis de textos e imagens, estando presente na sinalização ou interpretação de todo o conjunto patrimonial. De acordo com a Matriz de Classificação de Exibição (21) (VEVERKA, 1998, p. 21), os painéis são exibições "de tipo 3", onde o objeto exposto é inerte e a sua interação com o visitante também não necessita de movimento, assim como com objetos fixos, mapas, etc. Numa hierarquia de interesse dos visitantes por uma determinada exibição, os painéis com textos e imagens são os que menor carga atrativa exercem na audiência, o que sugere haver relação entre o interesse e a possibilidade de interação do visitante, e deste com o movimento do objeto exposto. 
Com o Programa de Salvaguarda e Valorização da (Real) Fábrica da Neve de Montejunto, o Centro de Interpretação Ambiental recebeu novos painéis interiores da Fábrica da Neve, que revelam os processos que envolvem a produção do gelo natural, seguindo o mesmo layout dos painéis afixados in situ, que minimizaram a falta de material de divulgação.

Os conteúdos, também elemento da componente da Interpretação, têm na investigação científica os pressupostos de atuação, tendo estado presente desde as suas primeiras ações do Programa de Salvaguarda e Valorização. A investigação é um elemento estruturante e fundamental a qualquer programa de conservação, e para este caso específico de aplicação num equipamento análogo a um museu representa uma função patente.

O que se conhece atualmente sobre a Fábrica da Neve de Montejunto, foi impulsionado pelos trabalhos prévios de investigação, ainda quando da elaboração de argumentos de defesa do reconhecimento da importância da classificação da Fábrica da Neve como condição à sua conservação (FOLGADO, 2010, p. 43).

O Programa de Salvaguarda e Valorização da (Real) Fábrica da Neve de Montejunto trouxe ainda contribuições relevantes para a divulgação do sítio arqueológico. Foi prevista uma série de publicações como componente da Interpretação, nas quais se incluem os materiais promocionais (cartazes, folders, guias, cartões postais), antes insuficientes; e uma monografia escrita por autores de reconhecida dedicação às temáticas relacionadas à Fábrica da Neve, a mais atualizada das referências bibliográficas.

A divulgação limitada é um problema "justificável" quando há falta de pessoal, pois sem equipe habilitada para receber os visitantes e realizar as atividades, não faz sentido criar grandes demandas com promoção. Entretanto, mesmo que não seja de interesse institucional captar novos públicos, não se pode perder de vista a utilidade de potencializar a internet como ferramenta auxiliar para fazer fruir a comunicação social, e mesmo a atenção ao público real, aquele que chega espontaneamente, motivado por conhecer. 
De acordo com Veverka (2003, p. 21) os princípios essenciais de comunicação usados no desenvolvimento de qualquer campanha promocional são a razão fundamental das comunicações interpretativas. A mídia deve efetivamente motivar, estimular, inspirar e impressionar os visitantes para que reajam à mensagem. $O$ responsável pela Interpretação deve usar seu conhecimento das técnicas de interpretação e aliar-se a outros profissionais de comunicação, arquitetura, biologia, design, etc. na construção multidisciplinar de programas, roteiros ou serviços interpretados.

\section{Considerações finais}

O primeiro ponto que pretendo refletir sobre a leitura da Interpretação do Patrimônio proposta neste artigo, é a não dissociação do patrimônio natural e cultural. O que evidencia a ação cultural do homem é a multiplicidade de interações "de saberes e de respostas a exigências econômicas, sociais, políticas, defensivas ou espirituais distintas" (FOLGADO, 2010, p. 121), sendo o ambiente natural o cenário, e a necessidade de adaptação a novos contextos uma constante.

Esse reconhecimento amplia a noção de patrimônio, e do próprio território que se confunde ora como espaço contentor, ora como objeto a ser musealizado (investigado, interpretado, conservado). Nesses termos, o arqueosítio musealizado da Fábrica Real da Neve, o Centro de Interpretação Ambiental, percursos terrestres constituem um conjunto de importância patrimonial, em polinúcleos interdependentes. Fica evidente após a leitura do espaço, que fazê-los funcionar de forma integrada é uma necessidade para fazer a audiência alcançar a revelação de significados do conjunto patrimonial, no todo e em partes, favorecendo a sensibilização, o surgimento de novas práticas de conservação patrimonial e a sua multiplicação.

A arqueologia é um bom argumento de valorização de um monumento. Aliado a isso, o fato de o percurso de visitação à Fábrica do Gelo figurar na maior parte dos casos, sendo o principal atrativo que motiva por si só a visitação à Serra do Montejunto, reforça a ideia inicial deste texto de se utilizar dos domínios da Interpretação para fazer fruir o patrimônio, em termos de manejo ecológico e gerenciamento operativo. 
Como tal, funciona por vezes com uma certa autonomia negligente, sem haver uma vinculação miníma de receptibilidade com o Centro de Interpretação Ambiental, seja pela limitação de tempo de grupos escolares com uma programação apertada; ou porque como "não é preciso passar" por ele para ir até a Fábrica da Neve, acontecendo inclusive de alguns destes nem darem-se conta ao fim da visita que há ali um espaço a serviço do visitante. As visitas guiadas são parte indissociável também das atividades recreativas realizadas com grupos escolares, sendo este o público majoritário.

A experiência prática de aplicação de técnicas de Interpretação no arqueosítio da Fábrica da Neve revela-nos um grau de enquadramento aos princípios de Tilden, nomeadamente na preocupação em conceber um sistema de sinalética junto aos vestígios in situ do que foi o espaço fabril, e na utilização destes elementos como partes de um todo integrado para relacionar o histórico de sua implantação naquele local, bem como para esclarecer quanto ao seu funcionamento nas diferentes fases. O fato de haver uma sequência lógica com início, meio e fim facilita o despertar de interesse nos visitantes, em detrimento de fatos contados pontualmente.

A função interpretativa de relacionar as informações disponibilizadas com a vida do visitante, entretanto, requer pesquisa sobre o perfil do público, instrumento de grande relevância para auxiliar o processo de investigação para aperfeiçoamento da experiência do visitante. As informações relativas às características comportamentais, hábitos de consumo, escolaridade, renda, etc., bem como a percepção deste público para com os atrativos e serviços disponibilizados são necessárias à tomada de decisão quanto ao planejamento e aprimoramento de ações voltadas à satisfação das necessidades do visitante e objetivos institucionais. Fica evidente portanto a necessidade de incorporar esse tipo de pesquisa para potencializar iniciativas de conservação patrimonial.

Apesar de não ser privilegiada uma maior combinação entre diferentes artes no incremento da comunicação para além dos textos e representação gráfica, algumas características destes como exibição são vantajosas, a exemplo da liberdade dada ao visitante de ler "quando", "quanto" e "como queira", incluindo "não fazê-lo". 
Sobretudo na impossibilidade de compor uma exposição com exibições de cargas variadas de atrativos, devemos estimular essa leitura oferecendo textos amenos, breves, claros e esteticamente interessantes, traduzidos no mínimo para o inglês, que são princípios básicos da interpretação do patrimônio.

Ainda na lógica da Interpretação, mesmo sendo o circuito de visitação criado pelo Programa de Salvaguarda e Valorização da (Real) Fábrica da Neve de Montejunto perfeitamente autoguiado, o trabalho do guia é de extrema importância para se conseguir fazer alcançar esta mensagem de conservação aos mais diferentes tipos de audiência, sobretudo no que se refere a uma programação para o público infantil.

Os pormenores da operação da visita, em termos de horários e dias de abertura, valor a ser cobrado ou não, equipe que se dedicará à recepção e condução de visitantes, e mesmo qual será a participação do Centro de Interpretação Ambiental na dinâmica cultural local ainda não estão divulgadas pela Comissão Diretiva da Paisagem Protegida da Serra do Montejunto, organismo responsável pela condução do Programa de Salvaguarda e Valorização da (Real) Fábrica da Neve de Montejunto.

A área da Fábrica da Neve de Montejunto intervencionada pelo Programa supracitado, encontra-se fechada desde dezembro de 2009, quando foram iniciadas as instalações de painéis e da iluminação no edifício dos silos de armazenamento, as últimas obras previstas antes da sua inauguração, ainda sem data marcada. Por essa razão não foi possível uma avaliação pormenorizada dos resultados em termos de alcance dos objetivos de comunicação e fruição cultural junto aos visitantes e moradores locais.

Observa-se, contudo, não haver melhor forma de proteger o patrimônio natural e cultural senão pela conscientização, já que é humanamente impossível salvaguardar todos os espaços de importância patrimonial, ao passo que uma vivência enriquecedora nestes espaços atuará como um fator inibidor a atos de vandalismo, já que o visitante precisa ser informado e sensibilizado, não ameaçado. 
Desta forma, pela reflexão apresentada, reitero a importância da presença da Interpretação na valorização da experiência do visitante pela revelação de significados, no controle e direcionamento do fluxo da visita, sem falar no melhoramento das condições do imóvel que o processo de restauro trouxe como medida de salvaguarda do sítio arqueológico.

O foco dado neste trabalho aos aspectos da Interpretação no Programa de Salvaguarda e Valorização da (Real) Fábrica da Neve de Montejunto, e identificação de suas práticas no território como uma todo, pode eventualmente ter deixado escapar algum tópico relevante, diante da multiplicidade de temas envolvidos na conservação do patrimônio. Este trabalho, portanto, não pretende ser conclusivo, mas servir de contribuição na circulação de informações sobre práticas que envolvam a Intrepretação do Patrimônio e os novos tipos de museus.

\section{Notas}

(1) A Fabrica da Neve é classificada Monumento Nacional em 1997, Decreto n. 67, de 31 de dezembro, por força do reconhecimento acerca do seu valor patrimonial, arqueológico, técnico e industrial; pela necessidade de salvaguarda e, emergência em conter as obras em curso de alargamento da área do quartel da Base $n^{\circ} 11$ da Força Aérea Portuguesa, localizado junto às ruínas (CUSTÓDIO, 2010, p. 84).

(2) O Movimento Internacional para a Nova Museologia (MINOM) surge como meio de intervenção e desconstrução de funções tradicionais dos museus quais sejam coleção, salvaguarda e exposição. Preconiza e defende um novo tipo de instituição museológica que busca alinhar o seu caráter disciplinar sócio-científico que configura tal modelo tradicional de museu; e seu estatuto de ciência humana, social, aplicada e de ação, determinada não apenas pelas mudanças sociais do entorno, como pelo contexto ecológico incluído. Fazer dos museus um instrumento a serviço da sociedade e de seu desenvolvimento, tornando-os mais participativos e interativos para as populações que os sustentavam era a intenção (FERNANDEZ, 2003, p. 17).

(3) O termo "Ecologia" (do grego oikos, casa, e logos, ciência) foi originalmente empregado em 1866, pelo zoólogo alemão Ernst Haeckel (1834-1919), e significa o estudo das relações entre os seres vivos e o ambiente onde vivem. O ambiente aqui referido é composto pelos organismos, populações, comunidades, ecossistemas e estes representam níveis de organização da estrutura e funcionamento ecológicos. Eles formam uma hierarquia de entidades progressivamente mais complexas.

(4) Interpreting Our Heritage, constituindo-se um marco teórico, e referência ainda atual para pesquisas mais recentes. No livro Tilden apresenta seis princípios da Interpretação, dedicando um capítulo a cada um deles: 1. 
Qualquer interpretação que não relacione de alguma forma o que está sendo mostrado ou descrito com algo presente na personalidade ou na experiência pessoal do visitante será estéril; 2 . Informação como tal não é interpretação. Interpretação é a revelação baseada em informação. Elas são coisas totalmente diferentes. Entretanto toda interpretação inclui informação; 3. A interpretação é uma arte que combina muitas artes, mesmo que os materiais apresentados sejam científicos, históricos ou arquitetônicos. Toda arte de alguma forma pode ser ensinada; 4. O objetivo principal da Interpretação não é a instrução, mas a provocação; 5 . A Interpretação deve atribuir maior importância ao todo e deve ser dirigida ao homem na sua integridade; 6. A interpretação endereçada às crianças não deve ser uma adaptação da apresentação feita para adultos. Deve se seguir uma forma fundamentalmente diferente de trabalho. Para se alcançar os melhores resultados será necessário um programa em separado.

(5) "Uma atividade educativa que busca revelar significados e relações através do uso de objetos originais, de contato direto com o recurso ou por mídia ilustrativa, não limitando-se a dar uma mera informação factual".

(6) Contudo, antes de morrer, Tilden diz que renunciaria à sua primeira definição, substituindo a expressão "atividade educacional" por "atividade recreativa" (MORALES, 2003, p. 18).

(7) Na Inglaterra, depois que a preservação e a interpretação do patrimônio ambiental urbano passaram a sensibilizar e a engajar grandes segmentos da população, o patrimônio cultural desenvolveu-se como principal recurso da indústria turística daquele país.

(8) Pertencente à cadeia montanhosa que inclui Serra da Estrela e Serra de Sintra.

(9) Arabis sadina e Saxifraga cintrana.

(10) Sendo que, entre elas, dez são consideradas ameaçadas pelo Livro Vermelho de Vertebrados de Portugal, outras extintas como a Gralha-do-bico-vermelho e o Calhandro Real. A águia perdigueira, o Bufo-real e o Andorinhão-real são consideradas raras a nível nacional.

(11) É resultado das ações de florestação dos serviços florestais a partir do início do século, que substituiu consideravelmente os matos por extensas áreas arborizadas.

(12) Castros de Pragança, Salvador e Rocha Forte.

(13) Paisagem Protegida corresponde ao que por vezes se tem designado por reserva de paisagem; com efeito, propõe-se salvaguardar áreas rurais ou urbanas onde subsistem aspectos característicos na cultura e hábitos dos povos, bem como nas construções e na concepção dos espaços, promovendo-se a continuação de determinadas atividades (agricultura, pastoreio, artesanato, etc.), apoiadas num recreio controlado e orientado para a promoção social, cultural e econômica das populações residentes e em que estas participam ativa e conscientemente.

(14) O tratamento para o armazenamento e transporte, compactação em partes menores e acondicionamento em palha e serrapilheira. 
(15) Ao "Neveiro Real, Julião Pereira" em 3 de novembro de 1795 e dirigido a Sebastião de Carvalho e Melo "poderia tomar as carruagens, bestas, barcos e tudo o mais que fosse necessário para a condução da dita neve para que se lhe não poria dúvida nem embargo alguns antes lhe seria dado todo o favor e ajuda que lhe pedisse..."

(16) Criados por determinação do rei como função/ ofício de produzir, recolher e proceder ao transporte para atender às necessidades da corte.

(17) Decreto de 3 de fevereiro de 1910. Diário do Governo, n. 79, II série, de 5 de Abril de 1930 - Tendo-se reconhecido a conveniência de proceder à aquisição da Quinta da Serra, sita no perímetro de arborização da Serra do Montejunto, sujeita ao regime florestal [...], já por constituir uma clareira onde havia toda a vantagem de plantar arvoredo, já por se prestar pela sua localização, para a instalação de viveiros e de um guarda-florestal”.

(18) O Relatório do Projeto de Arborização do Perímetro Floresta da Serra do Montejunto, da responsabilidade da Direção-Geral dos serviços florestais, de 1957, indica que quando do encerramento de sua laboração (que data 1885) - que a arborização estava comprometida progressivamente pela degradação dos solos, o que contribuía para esterilidade daqueles terrenos da montanha e para a destruição do manto vegetal (FOLGADO, 2010, p. 43).

(19) No interior do edifício do armazenamento, optou-se pela integração de um conjunto de painéis, que transmitisse uma informação mais aprofundada sobre a história do fabrico do gelo natural, não esquecendo o gelo artificial (FOLGADO, 2009, p. 124). A colocação destes painéis interiores no edifício mais nobre do conjunto fabril pretendeu valorizar a fruição desse espaço funcional relacionado com a ensilagem e a preparação do gelo para expedição (FOLGADO, 2009, p. 124)

(20) O termo é relativamente recente, provém dos antigos museus dos parques nacionais norte-americanos (MORALES, 2001, p. 13), e substitui expressões tradicionais como "museu do parque", "quartel-general" ou, ainda mais atual "centro da natureza", "centro de informação", ou "centro de visitantes".

(21) Essa matriz classifica a atratividade de uma exibição quanto ao grau de interesse que pode provocar no público, passando pela escala de 1 a 3 . As de "tipo 1" são as tipicamente interativas, que poderão ser manipuladas e geralmente são as unidades que necessitam de um maior gasto de tempo e energia por parte do visitante. As de "tipo 2" estão divididas em $2 a$ e $2 b$, sendo "2a" as que o visitante se move, mas a exibição é inerte, e " $2 \mathrm{~b}$ " as exibições em que a audiência é passiva, mas a exibição é dinâmica. Nas de "tipo 3", tanto o visitante como a exibição não necessitam de movimento para se relacionarem. (VEVERKA, 2001, p. 127).

\section{Referências Bibliográficas}

BARROS, Francisco; MARQUES, Paulo. Atlas das aves que nidificam na Serra do Montejunto. Torres Novas: ADSAICA - Associação de Desenvolvimento das Serras de Aire e Candeeiros D.L., 1999.

CARVALHO, Emanuel. Real Fábrica do Gelo de Montejunto: seu estudo e preservação. In: SEMINÁRIO DO PATRIMONIO DA REGIÃO OESTE, 1., 1996, Caldas da Rainha. Patrimônio Histórico: [Actas]. Caldas da Rainha: Grupo de Estudos, 1996. 
CUSTÓDIO, Jorge. A Quinta da Fábrica: A Real Fabrica de Atanados de João Mendes de Faria e Sucessores. Boletim Cultural Cira, Vila Franca de Xira: Camara Municipal de Vila Franca de Xira, n. 8. 1998.

Neveiros, contadores de neve e organização oficial e manufatureira da produção do gelo natural em Portugal. A propósito da fábrica da neve da Quinta da Serra, em Montejunto. In: A FÁBRICA de Neve da Serra do Montejunto. Cadaval: Câmara Municipal do Cadaval, 2010.

FERNÁNDEZ, Luis Alonso. Introdución a la nueva museología. Madrid: Alianza Editorial, 2003.

FERREIRA, Elisabete M. B. A arquitectura paisagista e a agregação do lugar. In: A FÁBRICA de Neve da Serra do Montejunto. Cadaval: Câmara Municipal do Cadaval, 2010.

FOLGADO. Deolinda. À procura de uma identidade da Real Fábrica de Gelo à Fábrica da Neve da Serra do Montejunto. Estado do Patrimônio, Lisboa: IPPAR, n. 9, 2006.

FOLGADO. Deolinda; LACERDA, Manuel. O programa de salvaguarda e valorização: do conceito à prática. In: $A$ FÁBRICA de Neve da Serra do Montejunto. Cadaval: Câmara Municipal do Cadaval, 2010.

HAM, Sam H. Interpretación Ambiental. Uma Guía Práctica para Gente com Grandes Ideias y presupuestos Pequeños. Colorado: Fulcrum Golden, 1992.

LOURENÇO, Fernando S.; CARVALHO, Emanuel. Real Fábrica de Gelo de Montejunto. In: JORNADAS ARQUEOLÓGICAS, 4., 1991, Lisboa, Actas... Lisboa: Associação dos Arqueológos Portugueses, 1991.

LOURENÇO, Fernando S.; ALMEIDA, Fernando A.; MESTRE, Victor. Real Fábrica do Gelo. Revista Semestral de Edifícios e Monumentos, Lisboa, n. 15, 2001.

MIRANDA, Jorge F. M.; GUERRA, Francisco J. Uso público y recepción en espacios naturales protegidos: la atención a los visitantes reales y potenciales. In: SEMINÁRIO PERMANENTE DE EDUCACIÓN AMBIENTAL EN ESPACIOS NATURALES PROTEGIDOS, 1992, Sevilla. Actas... Sevilla: Secretaria General de Medio Ambiente - M.O.P.T, 1996.

MORALES, Jorge. Guía practica para la interpretación del patrimônio: el arte de acercar el legado cultural al publico visitante. Sevilla: Difusión, 2001.

Técnicas de Interpretação do Patrimônio, 2003. 125p. Curso de Técnicas de Interpretação do Patrimônio, Faculdade de Turismo da Bahia, Salvador, nov. 2003.

MURTA, Stella Maris; ALBANO, Celina (Orgs). Interpretar o patrimônio: um exercício do olhar. Belo Horizonte: UFMG, 2002.

MURTA, S. M.; GOODEY, B. Interpretação do patrimônio para o turismo sustentável: um guia. Belo Horizonte: Sebrae (MG), 1995. 
TILDEN, Freeman. La interpretación de nuestro património. Sevilla: Asociación para la Interpretación del Patrimonio, 2006.

VEVERKA, J. A. Interpretative Master Planning: the essential planning guide for interpretative centers, parks, selfguide, trails, historic sites, zoos, exhibits, and programs. California: Ed Acorn Naturalist, 1998.

Porque os lugares de importância patrimonial necessitam de Interpretação para sobreviver por longo tempo. Turismo: tendências e debates, Salvador: Unidade Acadêmica das Faculdades Integradas Olga Metting, v. 5, n. 5, jan./dez., 2003.

\section{Créditos}

* Graduada em Turismo pela Fundação Visconde de Cairu, pós-graduada em Interpretação do Patrimônio com Comunidades pelas Faculdades Integradas Olga Mettig, especialista em Desenvolvimento Sustentável e Direito Ambiental pela Universidade de Brasília - UnB, mestranda em Museologia pela Universidade Nova de Lisboa. Bolsista do Programa Alban, monitora voluntária do Centro de Interpretação Ambiental da Paisagem Protegida da Serra do Montejunto.

email: ssa.karina@gmail.com 